\title{
Restriction fragment length polymorphism (RFLP) analysis of Blastocystis spp. in symptomatic and asymptomatic individuals from Alexandria, Egypt
}

\author{
Original \\ Article \\ Hend A El-Taweel ${ }^{1}$, Yasmine A Isaa ${ }^{2}$, Ghada A Shehata ${ }^{3}$, Ahmed Gaballah ${ }^{4}$, Wael \\ M Lotfy ${ }^{5}$, Mona M Tolba ${ }^{1}$
}

Departments of Parasitology ${ }^{1}$, Biochemistry ${ }^{2,3}$, Microbiology ${ }^{4}$, and Community Health ${ }^{5}$, Medical Research Institute ${ }^{1,4}$, Faculties of Medicine ${ }^{2}$, Science ${ }^{3}$ and Nursing ${ }^{5}$, Alexandria University $^{1,2,3,4}$, and Matrouh University ${ }^{5}$ Egypt

\begin{abstract}
Background: Blastocystis spp. is a unique enteric parasite commonly found in the intestines of humans and animals. In humans, prevalence up to $60 \%$ has been reported in tropical, subtropical, and developing countries. Currently 26 subtypes (STs) of Blastocystis have been described based on sequence analysis, 9 were reported in humans.

Objectives: The aim of the work was to determine the different genotypes of Blastocystis spp. in symptomatic and asymptomatic individuals in Alexandria city, Egypt.

Subjects and Methods: Examination of 100 stool samples was performed to detect Blastocystis collected from patients complaining of gastrointestinal (GI) disturbances and asymptomatic individuals. PCR restriction fragment length polymorphism analysis (PCR-RFLP) and sequencing of amplified products was performed for Blastocystis subtyping.

Results: Out of 47 fecal samples positive only for Blastocystis spp. by microscopy, 39 patients presented with symptoms and 8 were asymptomatic participants. Blastocystis small subunit rRNA (SSU rRNA) was successfully amplified from 27 samples; $24 / 39$ symptomatic and $3 / 8$ asymptomatic. Among symptomatic patients, four STs were identified; ST3 was the most common (55\%) followed by ST1 (20\%), ST4 (15\%) and ST2 (10\%). While ST2 and ST4 were identified only in patients having GI symptoms, ST1 and ST3 were found in both symptomatic and asymptomatic participants. Amplicons of 7 samples from symptomatic patients were not digested after incubation with the restriction enzymes and could not be genotyped.

Conclusion: Genotyping of Blastocystis spp. from fecal samples revealed the presence of four different subtypes: ST1, ST2, ST3 and ST4 with predominance of ST3. No statistically significant association could be observed between Blastocystis STs and clinical presentation of the studied subjects.
\end{abstract}

Keywords: Blastocystis spp.; subtypes; gastrointestinal symptoms; RFLP; sequencing.

Received: 15 August, 2020, Accepted: 12 November, 2020.

Corresponding Author: Mona M Tolba, Tel.: +20 1001870938, E-mail: mona.tolba@alexu.edu.eg

Print ISSN: 1687-7942, Online ISSN: 2090-2646, Vol. 13, No. 3, December, 2020.

\section{INTRODUCTION}

Blastocystisspp.areanaerobicorganismscolonizing the intestinal tract of humans and a wide range of animals ${ }^{[1,2]}$. An earlier study grouped this unicellular organism with yeasts, sporozoa or sarcodines ${ }^{[3]}$. However, sequence analysis of its complete SSU rRNA indicated that it should be included in Stramenopiles, a complex group of protozoa ${ }^{[4,5]}$. Globally, Blastocystis is one of the most common enteric organisms with higher prevalence rates in developing than in developed countries ${ }^{[6,7]}$. Faeco-oral route is believed to be the principle mode of transmission where low socioeconomic conditions, poor hygienic practice and consumption of contaminated water act as major risk factors $^{[8,9]}$.

Although Blastocystis has been identified in fecal samples since the early 1900s, it gained great attention only in recent decades when its pathogenic potential became a matter of debate ${ }^{[1]}$. Infection was demonstrated in both symptomatic and asymptomatic individuals ${ }^{[10]}$. While it was considered a commensal organism with no pathogenic role, its recording in parasitological stool reports was questioned ${ }^{[11]}$. Others linked Blastocystis to GI symptoms such as nausea, flatulence, and diarrhea ${ }^{[12,13]}$. Association with irritable bowel syndrome was also reported ${ }^{[14]}$.

It was proposed that the duration and intensity of infection and host genetic factors may influence infection outcome ${ }^{[1]}$. Colonization by different STs is one of the possible explanations for the inconsistent pathogenesis of Blastocystis ${ }^{[12,13,15]}$. Molecular methods based on analysis of SSU rRNA revealed that genus Blastocystis comprises 26 different STs among which, only nine STs were reported in humans 
(most prevalent are ST1-5 as well as other rarer STs, ST6-9 ${ }^{[16]}$. A previous study in Egypt detected ST1 in symptomatic patients and ST2 in asymptomatic persons while ST3 and ST4 were identified in both symptomatic and asymptomatic individuals ${ }^{[17]}$. Another study showed that ST3 is the most common one in fecal samples collected from Saudi patients with GI complaints ${ }^{[18]}$. Treatment of Blastocystis is generally recommended in symptomatic patients, regardless the infecting ST, when it is detected in the absence of other detectable enteric pathogens ${ }^{[10]}$. However, differences in sensitivity of Blastocystis STs to anti-microbial agents were described ${ }^{[19]}$. Identification of Blastocystis subtypes may, therefore, help in determining the need for treatment and prescription of the appropriate anti-parasitic drug. Moreover, characterization of Blastocystis subtypes may provide a clue for predicting the likely source of infection and understanding the dynamics of transmission ${ }^{[3]}$.

Recent reports on the distribution of Blastocystis subtypes are available from several countries and, in some cases, from different areas of the same country. In a large multi-center study in France, the distribution of Blastocystis subtypes in 141 positive stool samples concluded that most cases are caused by STs $1-4^{[20]}$. In a Brazilian rural community, subtyping of isolates from 85 Blastocystis isolates highlighted predominance of ST3 followed by ST1 and ST2 in equal percentages while ST4 and ST8 were less prevalent ${ }^{[21]}$. In an urban area of the same country, another study showed markedly lower prevalence of ST2 compared to ST3 and ST1 in 64 samples $^{[22]}$. In Egypt, studies investigating Blastocystis subtypes are limited. Data is only available from Cairo ${ }^{[23,24]}$, Ismailia ${ }^{[17]}$ and El Mansoura ${ }^{[25]}$. Based on the standard terminology described by Stensvold et al. ${ }^{[26]}$, a total of six STs (STs1-4 and STs 6,7) were identified in the mentioned Egyptian studies with dissimilar relative frequency.

The present work aimed to analyzeSTs of Blastocystis spp.in infected symptomatic and asymptomatic individuals from Alexandria, Egypt using PCR-RFLP analysis. Sequencing of the amplified products was performed on random samples for confirmation.

\section{SUBJECTS AND METHODS}

A cross sectional study was carried out to detect infection with Blastocystis spp. in 100 individuals referred to the Parasitology Laboratory of the Medical Research Institute, Alexandria University for routine parasitological examination during the period between April and August 2017. Subjects with Blastocystis-positive stool samples and with no other detectable parasite were enrolled in the study. Personal information as name, age, gender, and clinical history were recorded. Based on clinical presentation, participants were categorized as 'asymptomatic' if they had no GI symptoms or 'symptomatic' if they had any GI complaints such as diarrhea, abdominal pain, nausea, or flatulence.

Collection and processing of stool samples: Fresh stool specimens free of water or urine were collected in clean, dry sealed labelled plastic containers. At the Parasitology Department laboratory, each sample was mixed thoroughly and examined for Blastocystis spp. using saline and iodine wet mount smears and formalin ethyl-acetate sedimentation technique ${ }^{[27]}$.

DNA extraction and PCR-RFLP: DNA was extracted from Blastocystis positive fecal samples using the extraction kit Bioline fecal isolate DNA(UK) according to the manufacturer's instructions ${ }^{[28]}$. A PCR protocol was used to amplify a region of Blastocystis SSU rRNA gene using the thermal cycler (Beco, Germany); amplification was performed using the forward and reverse primers; RD3 (GGGATCCTGATCCTTCCGCAGGTTCACCTAC) and RD5 (GGGATCCTGATCCTTCCGCAGGTTCACCTAC), respectively ${ }^{[28]}$. The PCR was carried out in a $50 \mu \mathrm{l}$ reaction volume containing $10 \mu \mathrm{l}$ DNA extract, 25 $\mu$ l DreamTaq ${ }^{\circledR}$ GreenMaster Mix (Fermentas, USA), $1 \mu \mathrm{l}$ forward primer, $1 \mu \mathrm{l}$ reverse primer and $13 \mu \mathrm{l}$ nuclease-free water. The amplification steps included a first cycle of denaturation at $95^{\circ} \mathrm{C}$ for $3 \mathrm{~min}, 35$ cycles of denaturation at $95^{\circ} \mathrm{C}$ for $3 \mathrm{~min}$, annealing at $58^{\circ} \mathrm{C}$ for $30 \mathrm{sec}$, and extension at $72^{\circ} \mathrm{C}$ for $2 \mathrm{~min}$, and a final extension step at $72{ }^{\circ} \mathrm{C}$ for $5 \mathrm{~min}$. Amplification products and molecular weight marker (100 base pair DNA ladder, Bioron, Germany) were electrophoresed in $0.8 \%$ agarose gel stained with ethidium bromide and were visualized under UV transilluminator. Each PCR run included a positive control of a known PCR positive sample approved by sequencing from previous study in the department and a negative control of nuclease-free water $^{[29]}$.

The amplified products for the SSU rRNA gene were digested to determine the strain subtype of Blastocystis spp. using 3 restriction enzymes; Hinfl, Rsal, and Sau3Al ${ }^{[28]}$. Restriction digestion was performed at $37^{\circ} \mathrm{C}$ for 15 minutes for the first two enzymes and for one hour for the third one. The total volume of the reaction mix was composed of $25 \mu \mathrm{l}$ containing $10 \mu \mathrm{l}$ PCR product, $2.5 \mu \mathrm{l} 10 \mathrm{X}$ buffer, $1 \mu \mathrm{l}$ restriction enzyme and $11.5 \mu \mathrm{l}$ sterile nuclease-free water. The restriction fragments were separated by electrophoresis on $2 \%$ agarose gel stained with ethidium bromide and visualized with a UV transilluminator. Interpretation of the resulting products of digestion and identification of B. hominis subtypes were performed by comparison to patterns described by Clark $^{[28]}$ and modified according to the consensus terminology described by Stensvold et al. ${ }^{[26]}$.

Sequencing: For confirmation of RFLP typing results, the amplified products of randomly selected samples were sequenced. The amplicon bands were 
excised, and DNA was extracted using QIAquick Gel Extraction Kit (Qiagen, Hilden, Germany) according to the manufacturer's instruction. DNA sequencing of purified PCR products was performed using the BigDye $^{\mathrm{TM}}$ Terminator Cycle Sequencing Ready Reaction Kit (Applied Biosystems, Darmstadt, Germany). Nucleotide sequences were determined on an ABI Prism 310 genetic Analyzer (Applied Biosystems, Germany). Sequences obtained in the present study were analyzed and aligned with previously recorded sequences of Blastocystis using standard software BioEdit Version 7.0.5 (Sequence Alignment Editor). Comparison of the identified samples with those accessible in the GenBank Database was held using the BLAST (Basic Local Alignment Search Tool) program located at the databases of the NCBI (National Center for Biotechnology Information, Bethesda, MD, USA) (www.blast.ncbi.nlm.nih.gov/Blast.cgi).

Statistical analysis: Data were statistically analyzed using IBM SPSS software package version 20.0. (Armonk, NY: IBM Corp). Chi-square, Fisher's exact test or Monte Carlo corrections were used to test the association between variables. A $P$ value less than 0.05 was considered statistically significant.

Ethical Consideration: The protocol of the study was approved by the Research Ethics Committee of the Medical Research Institute (MRI), Alexandria University (IORG 0008812). An informed consent was obtained from each patient. Infected individuals were referred to a physician for treatment.

\section{RESULTS}

Out of 100 stool samples submitted to the Parasitology laboratory during the study period. Blastocystis spp. was detected microscopically in 63 samples $(63 \%)$ using saline and iodine wet mounts (Figure 1). It was found alone in $47(74.6 \%)$ of these samples and in conjunction with other protozoa $(E$. coli, G. lamblia, and D. fragilis) in 16 (25.4\%) samples.

Among 47 Blastocystis positive individuals with no other detectable parasites, 39 subjects (83\%) were symptomatic, and 8 subjects $(17 \%)$ were asymptomatic. Twenty-one subjects (45\%) were in the age group $20-<40$ years. In the other two age groups $(5-<20$ and $40-55$ years $)$ lower percentages were recorded in 12 (25\%) and in 14 (30\%) cases,

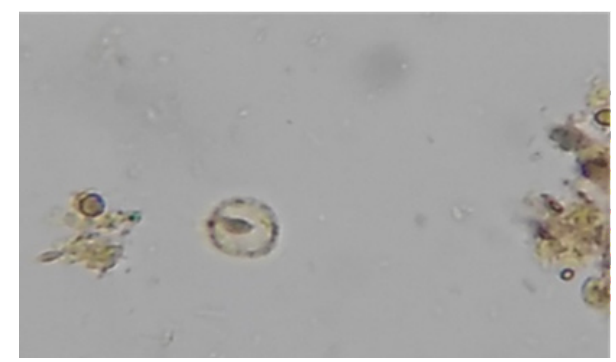

respectively. In the youngest age group, 92\% of the subjects were symptomatic compared to $86 \%$ and $76 \%$ of the oldest and middle age participants respectively. However, there was no statistically significant association between subjects' age and presence of GI symptoms. Regarding gender, GI symptoms were present in $86 \%$ of males and $78 \%$ of females with no statistically significant difference. (Table 1).

Out of 47 samples, amplification of Blastocystis spp. SSU rRNA produced a PCR product with the expected length (1800 bp) in 27 samples (Figure 2); 24 were from symptomatic and 3 from asymptomatic patients. Distinct patterns were obtained after digestion by restriction enzymes in 20 samples. Based on patterns described by Clark $^{[28]}$ and modification according to the standard terminology described by Stensvold et al. ${ }^{[26]}$, four Blastocystis subtypes were identified (Figure 3). ST3 was the most common, being detected in $11 / 20$ samples (55\%). This was followed by ST1 (4/20 samples: 20\%), ST4 (3/20 samples: $15 \%)$ and ST2 (2/20 samples: $10 \%)$.

Sequencing of the amplified products was performed in six randomly chosen samples that included two samples assigned by RFLP to ST1 and four samples assigned to ST3. Analysis of sequencing results of the six samples revealed Blastocystis subtypes concordant with the corresponding RFLP subtypes.

The demographic and clinical criteria of participants in whom Blastocystis spp. could be subtyped are shown in table (2). While STs 1 and 3 were detected in symptomatic and asymptomatic persons, STs 2 and 4 were identified only in symptomatic participants. In the youngest age group, samples that could be subtyped belonged to STs 1,3 , and 4 (one sample each). In the middle age group, ST 3 was the most common (6 samples) followed by ST 1 and 2 (each in 2 samples) and ST 4 (in one sample). Three STs (1, 3 and 4) were identified in the six genotyped samples of the older group with ST 3 being the most common (in 4 samples). Samples that could be genotyped belonged to 11 males and 9 females. The most common ST in males was ST 3 ( 9 cases), followed by STs 1 and 4 (each in one sample). Among females, the most common ST was ST1(3 samples) followed by STs 2, 3 and 4 (each in two samples).

Fig. 1. Blastocystis spp. in iodine wet mount smear (400 x). 
RFLP analysis of Blastocystis spp.

El-Taweel et al.

Table 1. Symptomatic and asymptomatic blastocystosis according to age and gender among 47 Blastocystis-positive individuals.

\begin{tabular}{lccc}
\hline \hline & $\begin{array}{c}\text { Symptomatic } \\
\text { No. (\%) }\end{array}$ & $\begin{array}{c}\text { Asymptomatic } \\
\text { No. (\%) }\end{array}$ & $\begin{array}{c}\text { Total } \\
\text { No. (\%) }\end{array}$ \\
\hline $\begin{array}{c}\text { Age in years } \\
\mathbf{5 -}\end{array}$ & $11(91.7)$ & $1(8.3)$ & $12(25.5)$ \\
$\mathbf{2 0 -}$ & $16(76.2)$ & $5(23.8)$ & $21(44.7)$ \\
$\mathbf{4 0 - 5 5}$ & $12(85.7)$ & $2(14.3)$ & $14(29.8)$ \\
\hline $\begin{array}{l}\text { Gender } \\
\text { Males }\end{array}$ & $25(86.2)$ & $4(13.8)$ & $29(61.7)$ \\
$\quad$ Females & $14(77.8)$ & $4(22.2)$ & $18(38.3)$ \\
\hline \multicolumn{1}{c}{ Total } & $39(83.0)$ & $8(17.0)$ & $47(100)$ \\
\hline \hline
\end{tabular}

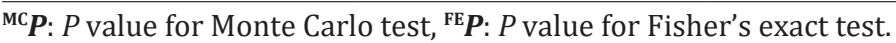

${ }^{*}$ Percentages calculated from the total in each age or gender group.

${ }^{\circledR}$ Percentages calculated from the total number of Blastocystis positive subjects with no other detectable parasites (n=47).

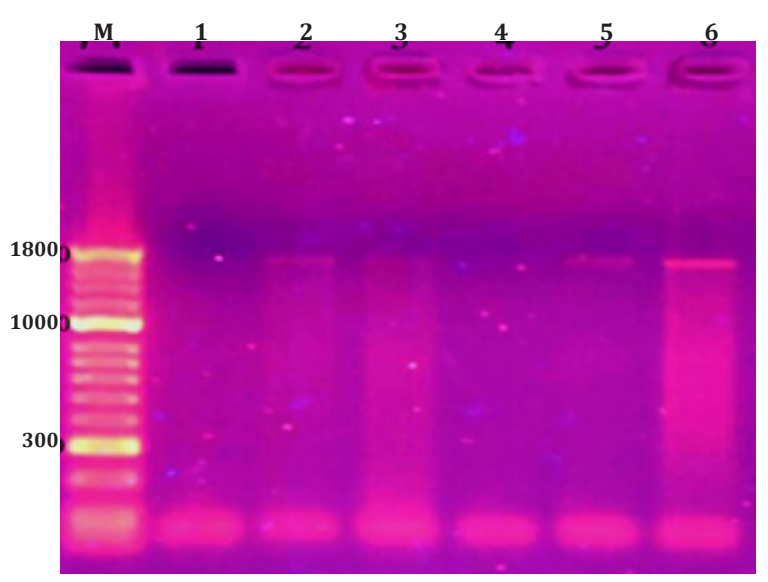

Fig. 2. Gel electrophoresis stained with ethidium bromide showing results of PCR amplification of Blastocystis SSU rRNA from microscopically positive fecal samples. Lane 1: Negative control; Lanes 2, 3 and 5: PCR positive samples showing one band at 1800 bp; Lane 4: PCR negative sample; Lane 6: positive control. $\mathrm{M}$ is the molecular weight marker (100-bp DNA ladder).

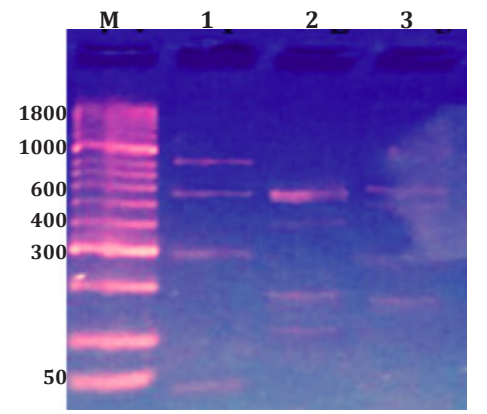

Fig. 3. RFLP pattern of a patient sample identified as ST1 after digestion with Hinfl enzyme (lane 1), Rsal enzyme (lane 2) and Sau3Al enzyme (lane 3). M is the molecular weight marker (100-bpDNA ladder).

Table 2. Blastocystis STs identified by SSU rRNA-RFLP and their associated demographic and clinical criteria among 20 participants with distinct patterns.

\begin{tabular}{|c|c|c|c|c|}
\hline \multirow{2}{*}{ Criteria } & \multicolumn{4}{|c|}{ Blastocystis subtypes } \\
\hline & ST1 & ST2 & ST3 & ST4 \\
\hline \multicolumn{5}{|l|}{ Age } \\
\hline 5- & 1 & 0 & 1 & 1 \\
\hline 20- & 2 & 2 & 6 & 1 \\
\hline 40-55 & 1 & 0 & 4 & 1 \\
\hline \multicolumn{5}{|l|}{ Gender } \\
\hline Male & 1 & 0 & 9 & 1 \\
\hline Female & 3 & 2 & 2 & 2 \\
\hline \multicolumn{5}{|l|}{ Clinical presentation } \\
\hline Symptomatic & 3 & 2 & 9 & 3 \\
\hline Asymptomatic & 1 & 0 & 2 & 0 \\
\hline Total & 4 & 2 & 11 & 3 \\
\hline
\end{tabular}

\section{DISCUSSION}

Blastocystis is a common intestinal eukaryote infecting several mammalian hosts. The wide genetic variation of Blastocystis isolates is thought to be linked to the clinical and epidemiological outcome of infection ${ }^{[30]}$. In the present study, parasitological examination of 100 fecal samples revealed Blastocystis detection rate of $63 \%$. In most samples (47/63; 74.6\%), Blastocystis was identified with no other intestinal parasitic infection. Previous studies in Egypt reported nearly similar high rates of Blastocystis infection. EL-Marhoumy et al. ${ }^{[31]}$ stated that Blastocystis was found in 53\% of studied preschool children. Eassa et al. ${ }^{[32]}$ detected Blastocystis in $54.5 \%$ of immunocompromised and $67.4 \%$ of immunocompetent individuals. Its prevalence is generally higher in developing countries compared to developed ones. It was suggested that travel to 
tropical countries increases the risk of Blastocystis infection $^{[33]}$. High prevalence was reported among immigrants $(52.7 \%)$ in Naples city in Italy ${ }^{[34]}$. A prevalence of $18 \%$ was reported in a multi-center study in France ${ }^{[20]}$. Different factors influence transmission and prevalence of Blastocystis infection including socioeconomic state, personal hygiene, animal contact and climatic conditions ${ }^{[7-9]}$.

In the present study, $45 \%$ of individuals infected solely with Blastocystis spp. were in the age group 20$<40$ years and $61.7 \%$ were males. El-Safadi et al. ${ }^{[20]}$ in France observed that the prevalence of Blastocystis sp. was significantly higher in the age group 15 to 49 years compared to older subjects. Paulos et al. ${ }^{[35]}$ in Spain found that children were more commonly infected by Blastocystis spp. A study in China reported inconsistent age and gender variations in different areas. Such differences in Blastocystis infection may be related to the associated exposure risk and environmental conditions rather than host physiological properties ${ }^{[36]}$.

Reports on the pathogenicity of Blastocystis spp. are contradictory ${ }^{[1,37]}$. The findings of our present study indicate that Blastocystis may be encountered in both symptomatic and asymptomatic individuals. In the absence of associated parasitic infection, the majority of Blastocystis infected subjects (39/47; 83\%) were symptomatic. This agrees with Mohamed et al. ${ }^{[18]}$ who found that $64 \%$ of Blastocystis positive subjects had GI symptoms. El Safadi et al. ${ }^{[20]}$ did not find any correlation between symptoms and infection with Blastocystis. It is to be noted that the present study was hospital based and therefore, data may not reflect the population's real distribution of symptomatic and asymptomatic Blastocystis infection. Generally, it was recommended to consider Blastocystis the causative agent of patient symptoms so long as no other etiology is identified ${ }^{[10]}$.

Our results also revealed that occurrence of GI symptoms in Blastocystis infection is not affected by the age or gender of infected persons. Jerez Puebla et $a l^{[38]}$ found that the rate of infection was significantly higher among school children having GI symptoms in comparison with asymptomatic ones while the group above 40 years old was more likely to have an asymptomatic infection. The authors attributed this to repeated infection with different STs as a result of bad hygienic practices in juvenile age. In contrast, Salvador et al. ${ }^{[39]}$ studied the epidemiologic and clinical profile of Blastocystis infected patients and found that asymptomatic patients were significantly younger.

While Santos and Rivera ${ }^{[40]}$ reported false negative results in only $2 / 21(9.5 \%)$ of cases, in our study out of 47 microscopically positive samples, Blastocystis SSU rRNA gene was successfully amplified by PCR in only 27 (57.5\%) samples. Our high record of false negative PCR result may be attributed to storage conditions of the samples prior to performing the PCR analysis which might have resulted in degradation of the organisms and consequently the $\mathrm{DNA}^{[41]}$. Inhibitors in stool such as polysaccharide complex, bile salts, bilirubin and hemoglobin degradation products could be another cause, the amount of these interfering compounds varies according to host diet and gut microflora ${ }^{[42]}$.

PCR-RELP analysis of Blastocystis subtypes was performed in the present study on DNA extracted directly from fecal samples. It was previously observed that this method is better than genotyping based on DNA extracted from stool culture which, in addition to being time consuming, may result in bias due to the possibility of preferential growth of some subtypes ${ }^{[30]}$. The RFLP pattern was confirmed in samples that could be sequenced denoting validity of the used protocol.

Our results showed that Blastocystis subtypes identified by RFLP included, in a descending order, ST3, ST1, ST4 and ST2. Confirmation of the results of subtyping was done by sequencing of some random samples. Nearly similar findings were previously reported using SSU rRNA RFLP or cloning and sequence analysis ${ }^{[23,24,43]}$. Another older Egyptian study using a PCR protocol based on sequence tagged site primers, reported similar predominance of ST3 (54.4\%) followed by ST1 (18.2\%) among 44 persons. However, this study reported the presence of two other subtypes namely ST6 and ST7 (18.2\% and 9.1\%, respectively $)^{[5]}$.

Worldwide, most Blastocystis infections in humans are attributed to STs 1-4. ST3 followed by ST1 were the most prevalent STs in in many countries as in Brazil[ ${ }^{[22]}$, France $^{[20]}$, United Arab Emirates ${ }^{[44]}$, Tunisia ${ }^{[45]}$, Saudi Arabia $^{[18]}$, Indonesia ${ }^{[46]}$ and Iran $^{[15]}$. Few studies showed slightly higher prevalence of ST1 compared to ST3 as in Philippines ${ }^{[47]}$ and Tanzania ${ }^{[48]}$. In Thailand, ST prevalence showed marked geographic variation with ST1 being the most common in the central region and ST3 in the north and northeast regions ${ }^{[49]}$. Variability in distribution of Blastocystis subtypes from one country to another and within the same country depend on the prevailing epidemiologic situation and climatic conditions ${ }^{[9,13,49]}$. Such variability may reflect difference in dynamics of transmission. Actually, a study in Malaysia illustrated that the prevalence of Blastocystis ST1 was higher during the wet season compared to the dry season while ST3 prevalence is nearly similar in both seasons suggesting subtype difference in susceptibility to adverse environmental conditions. Moreover, person to person transmission was found to play a role in transmission of ST1, ST2 and ST3, while the use of untreated water was identified as a risk factor for ST3 only ${ }^{[13]}$.

A striking higher prevalence of ST2 (62\%) compared to ST3 (17\%) and ST1 (13\%) was found in 63 samples in Spain ${ }^{[35]}$. Regional variation of ST2 distribution was described in a study conducted among migrant workers in Qatar where it was completely absent (0\%) 
from Western Asian Blastocystis-positive subjects but was detected in (5.3\%) of Africans and (9.7\%) of East Asian workers ${ }^{[50]}$.

Regarding ST4, increased evidence indicates that it is either absent or accounts for less than $4 \%$ of human infections as in Iran $^{[15]}$, France ${ }^{[20]}$, Brazil ${ }^{[22]}$, United Arab Emirates $^{[44]}$, Tunisia ${ }^{[45]}$ and Tanzania ${ }^{[48]}$. Although, ST4 is considered mainly a parasite of animals ${ }^{[51]}$, a relatively high distribution was observed in some European studies ${ }^{[12,52,53]}$. On the other hand, STs: 5, 6 and 7 are relatively uncommon and have been reported mainly from rural areas in association with the other common STs. The potential for zoonotic transmission of these STs was proposed ${ }^{[51]}$.

It is worth mentioning that Blastocystis ST1 and ST3 were detected in our study in both symptomatic and asymptomatic participants, ST2 and ST4 were found only in patients having GI symptoms. Studies investigating the association of STs with GI symptoms are contradictory. Our results are consistent with a large multicenter study conducted in France ${ }^{[20]}$. However, an association between ST1 infection and nausea and between ST3 infection and flatulence were reported in a Malaysian study ${ }^{[13]}$. A study in Italy found that ST4 was more common in patients with diarrhea ${ }^{[12]}$. It was proposed that intrinsic host factors in addition to parasite factors may play a role in determining the outcome of Blastocystis infection ${ }^{[13,48]}$.

In conclusion, Blastocystis is commonly spacing in routine examination for parasitic ova and cysts. Infection by Blastocystis may be symptomatic or asymptomatic regardless the individual's age or gender. Infection is caused by STs 1-4 with predominance of ST3. Most infections are most probably mixed subtypes.

Acknowledgment: The authors thank Mrs. Salwa Abd Elbadea from the Medical Biochemistry department, Faculty of Medicine, University of Alexandria, Egypt, for her technical assistance in the sample processing and PCR performance.

Authors contributions: El-Taweel HA designed and coordinated all field activities, experiments, analyses, and critically reviewed the manuscript. Issa YA organized bioassays, and drafted the manuscript. Shehata GA collected biological material organized bioassays, analyzed statistical data, and drafted the manuscript. Gaballah A performed genotyping and statistical analysis. Lofty WM assisted in the statistical analysis and critically reviewed the manuscript. Tolba MM coordinated collection of samples, biological analyses, and critically reviewed the manuscript.

Conflict of interest: The authors declare that there is no conflict of interest.

Financial statement: No financial support was provided.

\section{REFERENCES}

1. Tan KS. New insights on classification, identification, and clinical relevance of Blastocystis spp. Clin Microbiol Rev 2008; 21:639-665.

2. Denoeud F, Roussel M, Noel B, Wawrzyniak I, Da Silva C, Diogon $\mathrm{M}$, et al. Genome sequence of the stramenopile Blastocystis, a human anaerobic parasite. Genome Biol 2011; 12(3): R29.

3. Zierdt C H. Blastocystis hominis, a long-misunderstood intestinal parasite. Parasitol Today 1988; 4:15-17.

4. Arisue N, Hashimoto T, Yoshikawa H, Nakamura Y, Nakamura G, Nakamura F. Phylogenetic position of Blastocystis hominis and of stramenopiles inferred from multiple molecular sequence data. J Eukaryot Microbiol 2002; 49:42-53.

5. Hussein EM, Hussein AM, Eida MM, Atwa MM. Pathophysiological variability of different genotypes of human Blastocystis hominis Egyptian isolates in experimentally infected rats. Parasitol Res 2008; 102:853-860.

6. Scanlan PD, Stensvold CR, Rajilić-Stojanović M, Heilig HG, De Vos WM, O'Toole PW et al. The microbial eukaryote Blastocystis is a prevalent and diverse member of the healthy human gut microbiota. FEMS Microbiol Ecol 2014; 90:326-330.

7. El Safadi D, Gaayeb L, Meloni D, Cian A, Poirier P, Wawrzyniak I et al. Children of Senegal River Basin show the highest prevalence of Blastocystis sp. ever observed worldwide. BMC Infect Dis 2014; 14:164.

8. Abdulsalam AM, Ithoi I, Al-Mekhlafi HM, Ahmed A, Surin J, Mak JW. Drinking water is a significant predictor of Blastocystis infection among rural Malaysian primary schoolchildren. Parasitology 2012; 139:1014-1020.

9. Javanmard E, Niyyati M, Ghasemi E, Mirjalali H, Asadzadeh Aghdaei H, Zali MR. Impacts of human development index and climate conditions on prevalence of Blastocystis: A systematic review and meta-analysis. Acta Trop 2018; 185:193-203.

10. Roberts T, Stark D, Harkness J, Ellis J. Update on the pathogenic potential and treatment options for Blastocystis sp. Gut Pathog 2014; 6(1):17.

11. Andersen LO, Stensvold CR. Blastocystis in health and disease: are we moving from a clinical to a public health perspective? J Clin Microbiol 2016; 54:524-528.

12. Mattiucci S, Crisafi B, Gabrielli S, Paoletti M, Cancrini G. Molecular epidemiology and genetic diversity of Blastocystis infection in humans in Italy. Epidemiol Infect 2016; 144:635-646.

13. Noradilah SA, Moktar N, Anuar TS, Lee IL, Salleh FM, Manap SNAA et al. Molecular epidemiology of blastocystosis in Malaysia: does seasonal variation play an important role in determining the distribution and risk factors of Blastocystis subtype infections in the Aboriginal community? Parasit Vectors 2017; 10:360.

14. Rostami A, Riahi SM, Haghighi A, Saber V, Armon B, Seyyedtabaei SJ. The role of Blastocystis sp. and Dientamoeba fragilis in irritable bowel syndrome: a systematic review and meta-analysis. Parasitol Res 2017; 116:2361-2371. 
15. Khademvatan S, Masjedizadeh R, Yousefi-Razin E, Mahbodfar H, Rahim F, Yousefi E et al. PCR-based molecular characterization of Blastocystis hominis subtypes in southwest of Iran. J Infect Public Health 2018;11:43-47.

16. Maloney JG, Lombard JE, Urie NJ, Shivley CB, Santin M. Zoonotic and genetically diverse subtypes of Blastocystis in US pre-weaned dairy heifer calves. Parasitol Res. 2019; 118(2):575-582.

17. Abaza SM, Rayan HZ, Soliman RH, Nemr NA, Mokhtar AM. Subtype analysis of Blastocystis spp. isolates from symptomatic and asymptomatic patients in Suez Canal University Hospitals, Ismailia, Egypt. PUJ 2014; 7(1):56-67.

18. Mohamed RT, El-Bali MA, Mohamed AA, AbdelFatah MA, El-Malky MA, Mowafy NM et al. Subtyping of Blastocystis sp. isolated from symptomatic and asymptomatic individuals in Makkah, Saudi Arabia. Parasit Vectors 2017; 7;10:174.

19. Mirza H, Teo JD, Upcroft J, Tan KS. A rapid, highthroughput viability assay for Blastocystis spp. reveals metronidazole resistance and extensive subtype-dependent variations in drug susceptibilities. Antimicrob Agents Chemother 2011; 55:637-648.

20. El Safadi D, Cian A, Nourrisson C, Pereira B, Morelle C, Bastien $\mathrm{P}$ et al. Prevalence, risk factors for infection and subtype distribution of the intestinal parasite Blastocystis sp. from a large-scale multi-center study in France. BMC Infect Dis 2016; 16:451.

21. Barbosa CV, Barreto MM, Andrade RJ, Sodré F, d'AvilaLevy CM, Peralta JM et al. Intestinal parasite infections in a rural community of Rio de Janeiro (Brazil): Prevalence and genetic diversity of Blastocystis subtypes. PLoS One 2018; 9;13:e0193860.

22. Valença Barbosa C, de Jesus Batista R, Pereira Igreja $\mathrm{R}$, d'Avila Levy CM, erneck de Macedo H, Carneiro Santos HL. Distribution of Blastocystis subtypes isolated from humans from an urban community in Rio de Janeiro, Brazil. Parasit Vectors 2017; 10:518.

23. Elwakil HS, Talaat RM. Genetic analysis of Blastocystis hominis isolated from symptomatic and asymptomatic human hosts in Egypt. J Egypt Soc Parasitol 2009; 39:99-109.

24. Souppart L, Moussa H, Cian A, Sanciu G, Poirier P, El Alaoui $\mathrm{H}$ et al. Subtype analysis of Blastocystis isolates from symptomatic patients in Egypt. Parasitol Res 2010; 106:505-511.

25. Abu El-Fetouh NI, Abdelmegeed ES, Attia RA, ElDosoky I, Azab MS. Genotyping of Blastocystis hominis symptomatic isolates and kinetics of associated local CD3 and CD20 cell infiltrate. PUJ 2015; 8(2):115-122.

26. Stensvold CR, Clark CG. Current status of Blastocystis: A personal view. Parasitol Int 2016; 65 (6 Pt B):763771.

27. Garcia LS. Diagnostic Medical Parasitology. 6th Ed. ASM Press, Washington DC. 2016, pp. 27-37.

28. Clark CG. Extensive genetic diversity in Blastocystis hominis. Mol Biochem Parasitol 1997; 87:79-83.

29. Elsayad MH, Tolba MM, Argiah HA, Gaballah A, Osman MM, Mikhael IL. Electron microscopy of Blastocystis hominis and other diagnostic approaches. J Egypt Soc Parasitol 2019; 49(2):373-380.

30. Clark CG, van der Giezen M, Alfellani M, Stensvold CR. Recent developments in Blastocystis research. Adv Parasitol 2013; 82:1-32.

31. EL-Marhoumy SM, Abd EL-Nouby K, Shoheib ZS, Salama AM. Prevalence and diagnostic approach for a neglected protozoon Blastocystis hominis. Asian Pac J Trop Dis 2015; 5:51-59.

32. Eassa SM, Ali HS, El Masry SA, Abd El-Fattah AH. Blastocystis hominis among immunocompromised and immunocompetent children in Alexandria, Egypt. Ann Clin Lab Res 2016; 4:1-7.

33. Bart A, Wentink-Bonnema EM, Gilis H, Verhaar N, Wassenaar CJ, van Vugt $\mathrm{M}$, et al. Diagnosis and subtype analysis of Blastocystis sp. in 442 patients in a hospital setting in the Netherlands. BMC Infect Dis 2013; 13:38-39.

34. Gualdieri L, Rinaldi L, Petrullo L, Morgoglione ME, Maurelli MP, Musella V, et al. Intestinal parasites in immigrants in the city of Naples (southern Italy). Acta Trop 2011; 117:196-201.

35. Paulos S, Köster PC, de Lucio A, Hernández-de-Mingo M, Cardona GA, Fernández-Crespo JC et al. Occurrence and subtype distribution of Blastocystis sp. in humans, dogs and cats sharing household in northern Spain and assessment of zoonotic transmission risk. Zoonoses Public Health 2018; 65:993-1002.

36. Li LH, Zhang XP, Lv S, Zhang L, Yoshikawa H, Wu Z, et al. Cross-sectional surveys and subtype classification of human Blastocystis isolates from four epidemiological settings in China. Parasitol Res 2007; 102:83-90.

37. Stensvold CR, Suresh GK, Tan KS, Thompson RC, Traub RJ, Viscogliosi E et al. Terminology for Blastocystis subtypes--a consensus. Trends Parasitol 2007; 23:9396.

38. Jerez Puebla LE, Millán IA, Núñez Fernández FA. Frequency of blastocystosis and its association with clinical symptoms in 2 years of surveillance at "Pedro Kourí" Institute. Clin Microbiol 2014; 3:178.

39. Salvador F, Sulleiro E, Sánchez-Montalvá A, Alonso C, Santos J, Fuentes I, et al. Epidemiological and clinical profile of adult patients with Blastocystis sp. infection in Barcelona, Spain. Parasit Vectors 2016; 9:548.

40. Santos HJ, Rivera WL. Comparison of direct fecal smear microscopy, culture, and polymerase chain reaction for the detection of Blastocystis sp. in human stool samples. Asian Pac J Trop Med 2013; 6:780-784.

41. Shehab AY, Moneer EA, Allam AF, Khalil SS, Tolba MM. Intestinal Microsporidia infection in leukemic children: microscopic and molecular detection. Acta Parasitol 2020; doi: 10.1007/s11686-020-00283-2.

42. Gonçalves EM, Araújo RS, Orban M, Matté GR, Matté $\mathrm{MH}$, Corbett CE. Protocol for DNA extraction of Cryptosporidium spp. oocysts in fecal samples. Rev Inst Med Trop Sao Paulo 2008; 50:165-167.

43. Mokhtar AB, Youssef AI. Subtype analysis of Blastocystis spp. isolated from domestic mammals and poultry and its relation to transmission to their incontact humans in Ismailia governorate, Egypt. PUJ 2018; 11(2): 90-98. 
44. AbuOdeh R, Ezzedine S, Samie A, Stensvold CR, ElBakri A. Prevalence and subtype distribution of Blastocystis in healthy individuals in Sharjah, United Arab Emirates. Infect Genet Evol 2016; 37:158-162.

45. Ben Abda I, Maatoug N, Ben Romdhane R, Bouhelmi $\mathrm{N}$, Zallegua N, Aoun K et al. Prevalence and subtype identification of Blastocystis sp. in healthy individuals in the Tunis Area, Tunisia. Am J Trop Med Hyg 2017; 96:202-204.

46. Sari IP, Benung MR, Wahdini S, Kurniawan A. Diagnosis and Identification of Blastocystis subtypes in primary school children in Jakarta. J Trop Pediatr 2018; 64:208-214.

47. Adao DE, Dela Serna AO, Belleza ML, Bolo NR, Rivera WL. Subtype analysis of Blastocystis sp. isolates from asymptomatic individuals in an urban community in the Philippines. Ann Parasitol 2016; 62:193-200.

48. Forsell J, Granlund M, Samuelsson L, Koskiniemi S, Edebro H, Evengård B. High occurrence of Blastocystis sp. subtypes 1-3 and Giardia intestinalis assemblage B among patients in Zanzibar, Tanzania. Parasit Vectors 2016; 9:370.
49. Yowang A, Tsaousis AD, Chumphonsuk T, Thongsin $\mathrm{N}$, Kullawong N, Popluechai S et al. High diversity of Blastocystis subtypes isolated from asymptomatic adults living in Chiang Rai, Thailand. Infect Genet Evol 2018; 65:270-275.

50. Abu-Madi M, Aly M, Behnke JM, Clark CG, Balkhy H. The distribution of Blastocystis subtypes in isolates from Qatar. Parasit Vectors 2015; 8:465.

51. Ramírez JD, Sánchez LV, Bautista DC, Corredor AF, Flórez AC, Stensvold CR. Blastocystis subtypes detected in humans and animals from Colombia. Infect Genet Evol 2014; 22:223-228.

52. Koltas IS, Eroglu F. Subtype analysis of Blastocystis isolates using SSU rRNA-DNA sequencing in rural and urban population in southern Turkey. Exp Parasitol 2016; 170:247-251.

53. Forsell J, Granlund M, Stensvold CR, Clark CG, Evengård B. Subtype analysis of Blastocystis isolates in Swedish patients. Eur J Clin Microbiol Infect Dis 2012; 31:16891696. 